\title{
FANSUBBING: \\ O DIÁLOGO ENTRE A COMPETÊNCIA MIDIÁTICA E A PRODUÇÃO DOS FÃS DE FICÇÃO SERIADA
}

\author{
Fansubbing: \\ the dialogue between media literacy and the production of fans of serial fiction \\ Fansubbing: \\ el diálogo entre la competencia mediática y la producción de los aficionados de \\ ficción seriada
}

Daiana Sigiliano Doutoranda e mestre em Comunicação pela Universidade Federal de Juiz de Fora. daianasigiliano@gmail.com

Gabriela Borges

Professora e vice coordenadora do Programa de Pós-Graduação em Comunicação da

Universidade Federal de Juiz de Fora. gabriela.borges@ufjf.edu.br

\section{Resumo}

Ao abranger o domínio de conhecimentos, habilidades e o engajamento do público em relação aos conteúdos, a cultura de fãs estabelece uma relação direta com a competência midiática. Nesse sentido, a competência midiática contribui para a autonomia e o desenvolvimento da capacidade crítica dos cidadãos, estando presente tanto na maneira como consumimos os conteúdos midiáticos, quanto no modo como os produzimos. Ferrés e Piscitelli (2015) propõem uma metodologia de análise para avaliar e promover o seu desenvolvimento na cultura da convergência. A partir deste aporte teórico, este artigo tem como objetivo analisar as dimensões da competência midiática, presentes nas legendas produzidas pelos fãs de ficção seriada, no site Legendas.TV.

Palavras-chave: Competência Midiática. Cultura de fãs. Ficção seriada.

\begin{abstract}
By encompassing the domain of knowledge, skills, and public engagement in content, fan culture establishes a direct relationship with media literacy. In this sense, media literacy contributes to the autonomy and development of the critical capacity of citizens, being present both in the way we consume media contents and in the way we produce them. Ferrés and Piscitelli (2015) propose a methodology of analysis to evaluate and promote their development in the culture of convergence. From this theoretical contribution, this article aims to analyze the dimensions of media literacy, present in the subtitles produced by fans of serial fiction, in the site Legendas.TV.
\end{abstract}

Key words: Media literacy.Fan culture. Serial fiction. 


\section{Resumen}

$\mathrm{Al}$ abarcar el dominio de conocimientos, habilidades y el compromiso del público en relación a los contenidos, la cultura de fans establece una relación directa con la competencia mediática. En este sentido, la competencia mediática contribuye a la autonomía y el desarrollo de la capacidad crítica de los ciudadanos, estando presente tanto en la manera como consumimos los contenidos mediáticos, como en el modo como los producimos. Ferrés y Piscitelli (2015) proponen una metodología de análisis para evaluar y promover su desarrollo en la cultura de la convergencia. A partir de este aporte teórico, este artículo tiene como objetivo analizar las dimensiones de la competencia mediática, presentes en las leyendas producidas por los fans de ficción seriada, en el sitio.

Palabras clave: Competencia mediática. Cultura de fans. Ficción seriada.

\section{INTRODUÇÃO}

A convergência midiática amplificou e reconfigurou as práticas da cultura de fãs ${ }^{1}$ (PEARSON, 2010; BENNETT, 2014; LOPES et al., 2015). Nesse contexto, o ambiente digital não só estabelece uma relação simbiótica entre produtores e consumidores, mas contribui na propagação dos conteúdos produzidos pelos fãs. Conforme apontam Lopes et al. (2015, p. 22), "Novas perspectivas tecnológicas surgidas principalmente com a popularização da internet garantem noções diferentes de sociabilidade e interações entre os fãs”.

Para Bennett (2014), as mudanças propiciadas pela cultura da convergência podem ser sistematizadas em quatro pontos centrais: a comunicação, a criatividade, o conhecimento e o poder organizacional e cívico. Segundo a autora (BENNETT, 2014, p.7-11), na contemporaneidade os fãs têm novas formas de produzir, compartilhar, participar e se engajar em torno dos universos ficcionais. Isto é, as plataformas digitais permitem a troca e a replicação instantânea das informações, além de facilitarem as mobilizações contra o cancelamento dos programas e de debates relacionados às questões sociais e políticas (ROSE, 2011).

De acordo com Sandvoss (2005) e Jenkins et al. (2014) os fãs são um ponto de referência nas discussões sobre a produção e o consumo na contemporaneidade. Conforme ressaltam Jenkins et al. (2014, p. 56), esses grupos “[...] em específico têm sido inovadores no uso de plataformas participativas para organizar e responder a textos de mídia". Para os autores, os fãs "[...] abraçam as novas tecnologias conforme vão aparecendo, em especial

\footnotetext{
${ }^{1} \mathrm{O}$ termo fã se refere ao sujeito que tem uma relação passional e de profunda admiração por algo (uma franquia de mídia, um filme, uma HQ, etc.) ou por uma pessoa pública (cantor, ator, etc.) (JENKINS, 2015)
} 
quando esses recursos the oferecem novos meios de interagir social e culturalmente" (JENKINS et al., 2014, p.57).

Ao envolver o domínio de conhecimentos, habilidades e o engajamento do público em relação aos conteúdos, a cultura de fãs estabelece uma relação direta com a competência midiática² $^{2}$ (JENKINS, 2012; BORGES et al., 2017; HERRERO-DIZ,2017; SIGILIANO; BORGES, 2018). A partir deste contexto, este artigo tem o objetivo de analisar as dimensões da competência midiática que estão em operação no Legendas. TV³. Criado em 2006, o site, mantido por fãs, reúne mais de 280 mil legendas, gratuitas para download, de séries, filmes, documentários e reality shows.

Para refletirmos sobre essa questão adotamos a metodologia proposta por Ferrés e Piscitelli (2015), que abrange seis dimensões, cada uma delas relacionada ao modo como as pessoas recebem, interagem e produzem os conteúdos midiáticos. Neste trabalho,refletimos sobre a dimensão da tecnologia e dos processos de interação presentes nas legendas produzidas pelos fãs de ficção seriada.

\section{DIÁLOGOS ENTRE A COMPETÊNCIA MIDIÁTICA E A CULTURA DE FÃS}

As discussões sobre as tradições epistemológicas da competência midiática ressaltam a pluralidade do conceito em diversas áreas do conhecimento, tais como a Comunicação e a Educação (ROSENBAUM; BEENTJES; KONIG, 2008; POTTER, 2010; SCOLARI, 2016). Como pontua Scolari (2016, p. 4),

Uma breve revisão bibliográfica nos trará dezenas de definições sobre a 'competência midiática'. É um conceito flexível que evolui e se adapta as transformações do ecossistema midiático e às diferentes perspectivas teóricas ${ }^{4}$.

O autor afirma que a constante atualização do termo se dá pela necessidade dos pesquisadores em acompanharem as transformações da comunicação contemporânea. Nesse sentido, o conceito busca refletir as características, as possibilidades e os desdobramentos da ambiência midiática na qual está inserido.

\footnotetext{
${ }^{2}$ Alguns autores se referem ao conceito como alfabetização midiática, letramento midiático, literacia midiática, media literacy. Ver:Sigiliano; Borges, 2018.

${ }^{3}$ Disponível em: <http://legendas.tv/>. Acesso em: 1 jul. 2018.

${ }^{4}$ Livre tradução das autoras: Um repaso rápido por La bibliografía nos dejará decenas de definiciones de 'alfabetismo mediático'. Se trata de un concepto flexible, que ha ido evolucionando y adaptándo se a las transformaciones del ecosistema de medios y a las diferentes perspectivas teóricas.
} 
Os pontos destacados por Scolari (2016) podem ser observados no levantamento realizado por Potter (2010). A revisão bibliográfica feita pelo autor apresenta cerca de 40 definições do conceito. Entretanto, apesar da complexidade epistemológica os estudos sobre a competência midiática ressaltam a combinação de conhecimentos e de práticas políticas, sociais e culturais que habilitam os cidadãos a pensar criticamente sobre os meios de comunicação (LIVINGSTONE, 2004; POTTER, 2010; FERRÉS \& PISCITELLI, 2015; BORGES et al., 2017). Neste trabalho,adotamos a definição de Ferrés e Piscitelli (2015, p. 3) ; segundo os autores, a competência midiática é uma combinação de conhecimentos, habilidades e atitudes consideradas necessárias para um contexto determinado.

Para refletirmos sobre o diálogo entre a competência midiática e a cultura de fãs, é fundamental discutirmos sobre o modo como o público ávido ${ }^{5}$ se relaciona com os conteúdos. De acordo com Jenkins (2015) e Lopes et al. (2015) o fã se envolve emocional e intelectualmente com os universos ficcionais ${ }^{6}$. Nesse sentido, ao se tornar fã de algo e/ou alguém o sujeito midiático passa a se comprometer de outra forma com o conteúdo em questão, diferente, por exemplo, de um telespectador casual ${ }^{7}$. Como explica Jenkins (2015, p. 73), “assistir à televisão como fã envolve níveis de atenção diversos e convoca competências diversas de espectador, diferente de quando se assiste ao mesmo conteúdo de forma casual".

Desta forma, o público ávido estabelece laços profundos com a história, explorando ao máximo os arcos narrativos e as personagens, além de fazer uma leitura atenta da composição imagética e dos desdobramentos em outras plataformas. $\mathrm{O}$ envolvimento dos fãs com as tramas também abrange a produção de conteúdos e, consequentemente, a propagação e a ressignificação do universo ficcional. Como destacam Lopes et al. (2015, p. 18)

[...] em determinado momento, o fã poderá torna-se ele mesmo, um produtor ao perceber que os sentidos oferecidos pelos recursos ficcionais da trama podem ser ampliados, seja a partir de suas experiências pessoais, seja a partir de experiências compartilhadas em comunidades de fãs ou redes sociais.

\footnotetext{
${ }^{5}$ Neste trabalho, consideramos o público ávido como aquele que interage e se engaja em torno de conteúdos midiáticos.

${ }^{6}$ É importante frisar que neste trabalho estamos nos debruçando sobre os fãs midiáticos. Para Evans e Stasi (2014, p.7) esta subseção dos estudos de fãs abrange os fãs de música, de esportes, de celebridades, de itens de consumo e, principalmente, de cinema e de televisão.

${ }^{7}$ Para Jenkins (2008, p. 114), os telespectadores causais são aqueles que “[...] assistem a uma determinada série quando se lembram dela ou quando não têm nada melhor para fazer. [...] É mais provável que conversem ou executem outra atividade doméstica junto com o programa, em vez de dedicar lhe atenção total”.
} 
O diálogo entre a competência midiática e a cultura de fãs se torna mais nítido ao observarmos algumas práticas deste público. A competência midiática envolve não só o consumo crítico dos conteúdos, mas o modo como os sujeitos se expressam no atual ambiente de conectividade.

Os conteúdos produzidos pelos fãs engendram novos modos de aprendizagem. De acordo com Massarolo e Mesquita (2013, p.35) “[...] a produção dos fãs abrange tanto a interpretação textual quanto os comentários, análises, ensaios opinativos e boletins explicativos, permanecendo aberta ao compartilhamento de arquivos e à pluralidade de opiniões". Criada pelos fãs, as fanfictions são narrações em prosa de histórias fictícias (JAMISON, 2017). No âmbito das narrativas ficcionais seriadas, os conteúdos podem aprofundar e ampliar os arcos narrativos que já estão presentes no universo ficcional, além de abordar tramas que não foram exploradas pelos roteiristas. Para Thomas (2007) e Jenkins (2012) essa prática da cultura de fãs estabelece uma relação intrínseca entre a leitura crítica e a leitura criativa. Isto é, para propor novos desdobramentos para os arcos narrativos o fã deverá conhecer de forma detalhada o universo ficcional. Quanto mais apurado for o entendimento crítico do paratexto, mais coerente será a fanfiction. Conforme explica Jenkins (2012, p.20),

Uma boa história de fã referencia eventos-chave ou pedaços de diálogo como evidência para suportar sua interpretação particular dos motivos e ações dos personagens. Detalhes secundários são usados para sugerir que a história poderia ter ocorrido de forma plausível no mundo fictício mostrado no original. É certo que existem histórias ruins que não se aprofundam nos personagens ou caem em interpretações banais, mas a boa fanfiction mostra um profundo respeito pelo que gerou a fagulha na imaginação ou curiosidade do escritor-fã.

As fanfictions também estimulam a criatividade do público ávido ao propiciar a construção de personagens e de suas histórias. Dessa forma, o fã coloca em prática noções da expressão escrita como, por exemplo, a criação de uma identidade fictícia (persona), a elaboração de um ponto de identificação com os leitores, o encadeamento dos acontecimentos, a evolução do clímax, etc. (THOMAS, 2007). Ao compartilhar as fanfictions em plataformas como Spirit Fanfics $^{8}$, Nyah! Fanfiction ${ }^{9}$ os fãs ainda têm a oportunidade de trocar informações com os leitores, tornando o processo criativo mais dinâmico.

\footnotetext{
${ }^{8}$ Disponível em: <https://www.spiritfanfiction.com/>. Acesso em: 1 jul. 2018.

${ }^{9}$ Disponível em: <https://fanfiction.com.br/>. Acesso em: 1 jul. 2018.
} 
De acordo com Martin (2014), o ambiente de convergência possibilita a emersão do fã-crítico. O autor afirma que o público ávido cria repositórios colaborativos, tais como sites especializados, fóruns e Wikis com informações detalhadas sobre o universo ficcional. Para Herrero-Diz (2017), os fãs têm uma predisposição a explorar as tecnologias e, principalmente, as mídias sociais, de maneira pertinente, esmiuçando todas as suas potencialidades. O ponto ressaltado pelo autor pode ser observado na maior plataforma colaborativa de fãs do mundo, a Wikia - Home of Fandom ${ }^{10}$. Atualmente, o site contém 382 mil páginas destinadas a filmes, vídeo jogos, livros e programas televisivos e recebe 191 milhões de acessos mensais. Todo o conteúdo vinculado na Wikia é elaborado de maneira colaborativa entre os membros. Além de abranger informações gerais sobre as atrações, tais como a audiência dos episódios, as fichas técnicas dos atores e atrizes, a biografia dos personagens, o site auxilia na compreensão da complexidade narrativa das produções. Como, por exemplo, a página ${ }^{11}$ de $M r$. Robot (USA Network, 2015-presente), que tem uma seção dedicada à explicação das referências presentes na grafia dos títulos dos episódios. Nesse contexto, os fãs se mobilizam para reunir informações relevantes do universo ficcional, explorando de modo significativo as potencialidades da arquitetura operacional ${ }^{12}$ das plataformas.

Outra prática popular na cultura de fãs são as ressignificações do paratexto pautadas pelo humor. Segundo Jenkins $(2015$, p.55) os telespectadores ávidos “[...] têm prazer em construir conexões intertextuais entre uma ampla gama de textos". A popularização das mídias sociais e das ferramentas de edição de textos, vídeos e imagens contribuíram para a difusão, por exemplo, dos memes ${ }^{13}$ e dos remix produzidos pelos fãs. Os memes introduzem diversas camadas interpretativas aos universos ficcionais, nesse sentido o conteúdo compartilhado pelo público ávido pode ironizar questões ligadas tanto à trama quanto a assuntos do cotidiano. Como, por exemplo, os memes criados pelos fãs de Grey's Anatomy (ABC, 2005-presente) que repercutem os desdobramentos dos arcos narrativos dos episódios, a carga dramática característica das séries de Shonda Rhimes e também estabelecem uma correlação com aspectos externos à ficção como as decepções amorosas, o estresse no trabalho, etc.

\footnotetext{
${ }^{10}$ Disponível em: <http://www.wikia.com/fandom>. Acesso em: 1 jul. 2018.

${ }^{11}$ Disponível em: <http://mrrobot.wikia.com/wiki/Mr._Robot_Wikia〉. Acesso em: 1 jul. 2018.

12 Neste artigo, entendemos arquitetura operacional como a forma de funcionamento (sistema operacional, interface e configuração) e de acessibilidade (modo de interação intuitiva, desenvolvimento e disponibilidade de aplicações) de um dispositivo e/ou plataforma.

${ }^{13}$ Gleick (2013, p. 17) define o meme como “[...] um replicador e um propagador - uma ideia, uma moda, uma corrente de correspondência".
} 
Considerado um dos tipos de remix mais produzidos pelos fãs, o crack mistura sequências da história com músicas, memes e outros conteúdos audiovisuais. Segundo Monk (2016), os vídeos exploram, de modo geral, a comédia e raramente são compreendidos fora do fandom $^{14}$. $\mathrm{O}$ autor pontua que o crack reflete as percepções que os fãs têm de determinados acontecimentos da trama. Exibida pelo canal estadunidense $\mathrm{ABC}$, a série OnceUpon a Time (2011-presente) possui inúmeros vídeos contestando alguns desdobramentos da história, os fãs intercalam cenas dos episódios com trechos de videoclipes e virais para ironizarem a atração.

Desta forma, a cultura de fãs estabelece uma relação intrínseca com a competência midiática. Seja pelo modo como consomem as tramas e/ou produzem os conteúdos, os fãs possuem um entendimento crítico dos programas. O profundo conhecimento que o público ávido tem do paratexto não só reforça os arcos narrativos, mas explora diversas vertentes do universo ficcional.

\section{FANSUBBING: NOVAS FORMAS DE PRODUÇÃO E DISTRIBUIÇÃO}

As novas tecnologias e o ambiente de convergência propiciam a alteração dos fluxos de mídia (PEARSON, 2010; JENKINS et al. 2014). Isto é, os fãs passam a influenciar, mesmo que indiretamente, a produção e distribuição dos conteúdos midiáticos. Conceituado como fansubbing, a produção e o compartilhamento de legendas de filmes, séries, reality shows e animês se popularizou no Brasil no início dos anos 2000. De modo geral, esta prática da cultura de fãs abrange quatro etapas: a tradução do conteúdo para o idioma local, a sincronia das legendas com o vídeo, a revisão do arquivo e a postagem da legenda no formato . $\mathrm{srt}^{15}$.

Criado em 2006, o Legendas.TV é o maior site de legendas em atividade no Brasil. Na plataforma, que recebe mais de 1,3 milhão de acessos mensais, é possível enviar e baixar legendas gratuitamente. O envio dos conteúdos pode ser feito individualmente e/ou pelas equipes de legenders ${ }^{16}$, que reúnem um grupo de fãs para produzir as legendas de determinado programa. Os gastos com o servidor são mantidos pelos administradores e por alguns colaboradores. Para ajudar financeiramente o Legendas.TV o usuário deve se tornar

${ }^{14} \mathrm{O}$ fandom se refere a um conjunto de fãs, em sua tradução literal o termo faz referência há algo como reino dos fãs', pela presença do sufixo dom proveniente de kingdom (reino) (JENKINS, 2015). Esta subcultura de fãs é caracterizada pelo sentimento de companheirismo e solidariedade por aqueles que compartilham os mesmos interesses.

${ }^{15}$ O SubRip ou ,srt é um formato de arquivo de texto editável usado para armazenar o texto e o tempo em legendas de vídeos.

${ }^{16}$ Fãs que produzem as legendas. 
um 'Assinante VIP', o título garante praticamente o mesmo acesso aos usuários que não são colaboradores, com exceção de poder testar algumas funções da plataforma em primeira mão e a redução de anúncios na página.

No âmbito das narrativas ficcionais seriadas, o tempo médio de produção de uma legenda varia de acordo com a popularidade da atração. Segundo Guga ${ }^{17}$, que integra a equipe InSubs, umas das mais antigas do Legendas.TV, quando o conteúdo gera muitos downloads todo o processo de tradução é feito durante a madrugada, dessa forma a legenda é disponibilizada no site seis horas após a exibição do episódio na TV (in CALAZANS, 2011). O fã afirma que geralmente a produção do conteúdo envolve, em média, sete pessoas (in CALAZANS, 2011). A equipe de legenders se reúne virtualmente para dividir as tarefas e inicia a tradução para o português a partir de arquivos em srt ou, em alguns casos, pelo próprio áudio da série (in CALAZANS, 2011). Como completa Guga, "Depois da tradução, a legenda é toda sincronizada e então passa para a revisão, onde é feita a correção gramatical, estética, da sincronia e etc, onde é feito o produto final" (in CALAZANS, 2011, ONLINE).

Discutida inicialmente por Thompson (1971), a economia moral se refere às normas de valor moral e social e os entendimentos mútuos que permitem que as duas partes envolvidas conduzam negócios. Segundo Jenkins et al. (2014) muitas práticas da cultura de fãs são norteadas pela economia moral. Os autores pontuam que nesta relação "Todos os participantes precisam sentir que as partes envolvidas estão se comportando de um modo moralmente adequado" (JENKINS et al., p. 83, 2014).

No Legendas.TV a economia moral pauta tanto a relação dos legenders com os outros legenders e usuários do site, quanto dos fãs com as produtoras. De acordo com Jenkins et al. $(2014,94)$

[...] quando existe uma economia moral firme, o público geralmente policia suas próprias ações, chama a atenção daqueles que acha que prejudicam a integridade de uma plataforma ou daqueles que minam acordos informais com produtores e distribuidores comerciais.

A designação da produção das legendas realizada pelos fãs e as equipes é feita em comum acordo com os administradores Legendas.TV. Como explica Guga, "se uma equipe quer uma série nova, ele deve pedir a reserva à administração e se seguir os prazos dados pelo site, a série é da equipe e ninguém pode pegar. É um acordo feito entre a administração e as equipes parceiras" (in CALAZANS, 2011, ONLINE). Nesse contexto, existe um acordo feito

${ }^{17}$ Para manter seu anonimato o fã optou por adotar um pseudônimo na reportagem do jornal O Globo (CALAZANS,2011). 
previamente que é respeitado durante todo o período que a série estiver no ar, mesmo que a postagem da legenda atrase, dentro do períodoestipulado pelo site, o programa continua sob responsabilidade do fã e/ou da equipe.

A relação entre os legenderse os usuários do site, isto é, aqueles que apenas realizam o download, também reflete a percepção dos valores da economia moral. Todas as legendas disponíveis no Legendas.TV apresentam um aviso alertando que aquele conteúdo é para uso pessoal e o compartilhamento e comercialização são proibidos. Além disso, a mensagem divulga um número para o usuário denunciar às autoridades responsáveis, caso estas regras de veiculação não sejam cumpridas. Dessa forma, cabe aos próprios usuários do site fiscalizar se os acordos da plataforma estão sendo cumpridos.

De acordo com Jenkins (2014, p. 85) “contando que os fãs não obtenham lucro, alguns donos de conteúdo optam por ignorar o uso de material em troca do trabalho que os fãs realizam para testar mercados e educar potenciais clientes". Entretanto, apesar de atualmente o Legendas.TV operar sem restrição alguma dos canais e produtoras, mantendo o acordo tácito de não comercializar os conteúdos, os fãs já tiveram divergências com as empresas. Em fevereiro de 2009, o site ficou fora do ar em decorrência de uma sanção da Associação Anti Pirataria de Cinema e Música, a APCM. O portal de notícias G1 (2009) publicou um comunicado da associação que defendia os interessantes de estúdios como a Warner e a Universal.

A APCM confirma a informação de que solicitou a retirada do site Legendas TV da rede mundial de computadores, "É importante ressaltar que a ação aconteceu porque seus usuários estavam violando os direitos autorais. Quando um usuário faz a legenda não autorizada de uma obra audiovisual ele fere o trabalho de toda uma cadeia produtiva: produtores, autores, atores, atrizes, câmeras, roteiristas, diretores, marketeiros, produção de fábrica, do próprio tradutor e etc", disse o órgão em comunicado oficial (G1, 2009, ONLINE).

Em resposta a nota da APCM o Legendas.TV criou um blog para tirar as dúvidas dos usuários sobre o fechamento do site. Eles afirmaram que não tinham qualquer tipo de retorno financeiro com as legendas e, por isso, as acusações da associação não eram verdadeiras.

Vamos apenas mudar de datacenter e voltaremos em breve. Não consideramos a possibilidade de tirar o site do ar. E não tememos pelo site por um motivo simples: o Legendas.TV é apenas um ponto de encontro de milhares de pessoas. Se ele, por algum motivo extraordinário, deixar de existir, as pessoas continuarão se encontrando e fazendo suas legendas em outro lugar (LEGENDAS.TV, 2009, ONLINE). 
Jenkins et al. (2014) afirmam que as mudanças unilaterais nas transações estabelecidas pela economia moral afetam a relação de fãs e produtores. Como pontuam os autores:

Os fãs defendem os direitos e as práticas que foram tidos como certos por muitos anos, tais como a prática antiga de criar 'fitas gravadas' ou outras compilações de material citado. As empresas, por outro lado, querem reprimir os comportamentos que veem como prejudiciais e que tenham um impacto muito grande na era digital (JENKINS et al., 2014, p.85).

Após a represália da APCM os fãs que produzem legendas para o Legendas.TV ficaram mais atentos com a adoção de pseudônimos para creditar os conteúdos. Porém, apesar dos episódios isolados de fechamento, o site continua em plena atividade e é atualizado diariamente com novos conteúdos.

Em novembro de 2017, os legenders tiveram outra divergência com as empresas. Segundo as reportagens dos sites Pipoca Moderna e Jovem Nerd, o canal pago Fox Premium teria usado durante a exibição da série Manhattan (WGN America, 2015-2016) as legendas produzidas pelo grupo $\operatorname{InSanos}^{18}$ (PRADO, 2017; VAL, 2017). Os fãs afirmaram que a autoria do conteúdo poderia ser comprovada pelo modo como o 'S' maiúsculo estava sendo usado $^{19}$ nas palavras.

Figura 1- O grupo de legenders InSanos ironiza a legenda usada pelo canal pago Fox Premium.

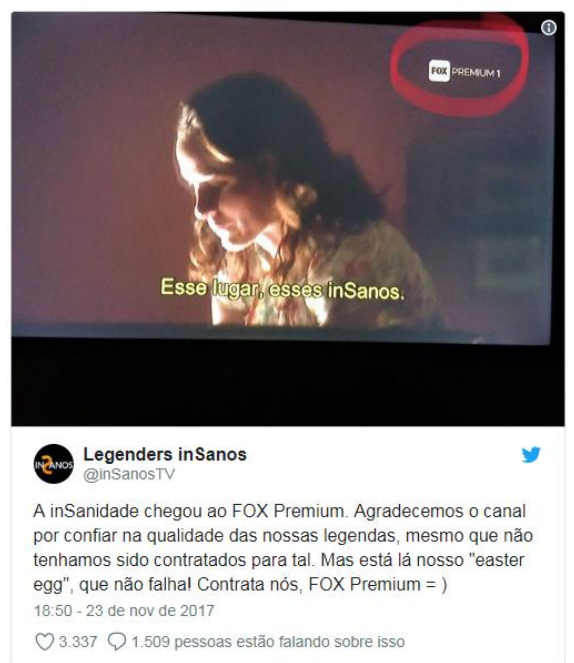

Fonte: Twitter ${ }^{20}$.

\footnotetext{
${ }^{18}$ Disponível em: <http://www.insanos.tv/>. Acesso em: 17 jul. 2018

${ }^{19}$ Os legenders adotam essa grafia para fazerem alusão ao nome do grupo.

${ }^{20}$ Disponível em: 〈https://bit.ly/2mnprgH>. Acesso em: 1 jul. 2018.
} 
No mesmo dia em que o episódio foi ao ar na emissora os legenders postaram no perfil do grupo no Twitter uma captura de tela de uma cena da trama com a 'marca registrada' do InSanos e um pequeno texto ironizando a situação. Mesmo com a grande repercussão nas redes sociais, o canal não se pronunciou sobre o uso da legenda.

\section{LINGUAGEM, TECNOLOGIA E PROCESSOS DE INTERAÇÃO: UMA ANÁLISE SOBRE O PROCESSO DE PRODUÇÃO DE LEGENDAS NO SITE LEGENDAS. TV}

Para operacionalizar metodologicamente as discussões sobre a competência midiática, Ferrés e Piscitelli (2015, p. 8-14) definiram seis dimensões a partir das quais os indicadores são elaborados. Estes indicadores se relacionam tanto ao âmbito de análise, isto é, a forma como as pessoas recebem e interagem com as mensagens, quanto ao âmbito de expressão, que se refere ao modo como as mensagens são produzidas pelas pessoas. É importante ressaltar que as dimensões estabelecidas pelos autores estão inter-relacionadas, ou seja, esta separação é feita para que possamos analisar didaticamente cada uma delas. São elas: linguagem, ideologia e valores, estética, tecnologia, processos de interação e de produção e difusão. Neste trabalho,analisamos as dimensões da linguagem, da tecnologia e dos processos de interação que estão em operação no processo de produção de legendas feitas pelos fãs de ficção seriada no site Legendas.TV.

Segundo Ferrés e Piscitelli (2015), a dimensão da linguagem abrange a capacidade de interpretar e avaliar diferentes códigos de representação e a sua função na mensagem; a capacidade de compreender o fluxo de histórias e informações de múltiplas mídias e formatos; a capacidade de se expressar e de escolher entre distintos sistemas de representação e a capacidade de editar produtos existentes, dando a eles um novo significado e valor. Além do conhecimento intrínseco de outro idioma, a tradução realizada pelos fãs considera elementos específicos de cada série. Nesse sentido, o processo envolve desde a tradução da língua estrangeira, que na maioria das vezes é o inglês, até a adaptação do texto para os usuários do site.

Ao traduzir os diálogos de um episódio o legender considera a proposta da série, por exemplo, as tramas do canal estadunidense CW são voltadas para o público adolescente, dessa forma é fundamental que as gírias sejam adaptadas para o contexto brasileiro. Isso também acontece com as séries médicas tais como Grey's Anatomy e The Resident (Fox, 2018-atual), os termos técnicos da área são traduzidos com base nas nomenclaturas adotadas no Brasil. A adaptação das palavras fica ainda mais complexa em tramas que são baseadas em livros já 
traduzidos no país como, por exemplo, Game of Thrones (HBO, 2011-2019) e Sharp Objects (HBO, 2018). Neste caso, os legenders têm dese pautar na tradução feita pela editora responsável e padronizar as legendas dos episódios.

A dimensão da linguagem, discutida por Ferrés e Piscitelli (2015), também pode ser observada no uso de siglas. Na série Halt and Catch Fire (AMC, 2014-2017) os fãs criavam pequenos textos explicativos sobre as siglas dos códigos de programação citados pelos personagens na trama. No final de cada episódio, os legenders sistematizavam as principais informações dos termos, ajudando na contextualização do universo ficcional da atração. Desse modo, ao produzir uma legenda o fã considera diversos elementos que podem interferir na interpretação dos usuários do Legendas.TV. Em outras palavras, o legender faz uma leitura crítica do conteúdo para verificar quais alterações e adaptações são pertinentes e, posteriormente, incorpora na legenda.

Para Ferrés e Piscitelli (2015), a dimensão da tecnologia envolve a compreensão do papel da tecnologia na contemporaneidade; a habilidade de interagir, manusear e produzir conteúdos em ambientes hipermídia e a capacidade de adaptar ferramentas tecnológicas e conteúdos aos objetivos comunicativos almejados. Todos os pontos destacados pelos autores podem ser observados no Legendas.TV. O sistema operacional do site vai ao encontro das necessidades dos fãs, ao acessar a página as principais seções são rapidamente identificadas e apresentam uma navegabilidade intuitiva. O usuário pode visualizar as legendas com o maior número de downloads da semana, os títulos que estão em processo de tradução, as últimas legendas adicionadas e as informações gerais (sobre, cadastro, login e contato). Desta forma, o Legendas.TV é estruturado e mantido pelos fãs de acordo com o propósito central do site, isto é, produzir e compartilhar legendas gratuitamente. 
Figura 2 - Na primeira imagem vemos o modo como algumas informações do site são organizadas, na segunda imagem é possível observar os detalhes de cada um dos arquivos postados.

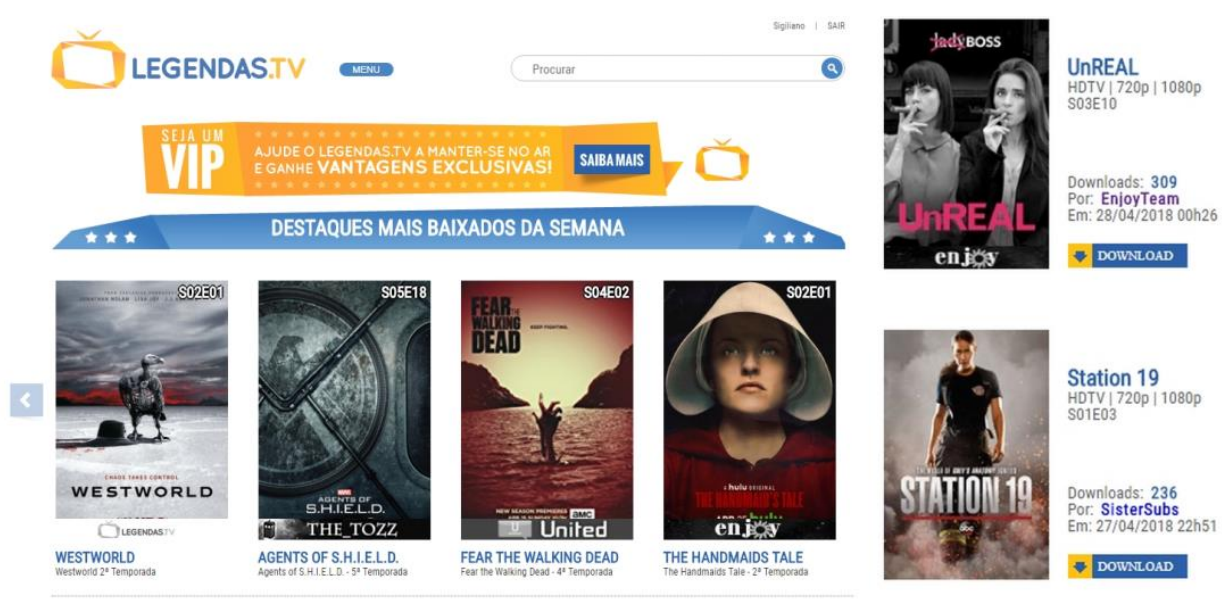

Fonte: Legendas.TV ${ }^{21}$.

O processo de produção das legendas, principalmente o realizado pelas equipes de fãs, também é pensado de uma maneira didática e funcional. Ao acessar o perfil de equipes como, por exemplo, InSubs, United e TecSubs, é possível realizar o download de um 'guia de legendagem'. O arquivo no formato pdf. reúne instruções técnicas de como produzir uma legenda. Dividido em sete capítulos o tutorial indica os softwares usados, as diretrizes de formatação e o passo a passo de todas as etapas de produção, desde a tradução até a postagem. Como discutiremos mais adiante, o guia disponibilizado pelas equipes não só ressalta o caráter colaborativo da produção de legendas, mas o profundo conhecimento que os fãs têm das questões técnicas que envolvem essa forma de conteúdo. Além disso, o arquivo contém referências bibliográficas sobre a tradução de produtos audiovisuais e dicionários de expressões estrangeiras.

${ }^{21}$ Disponível em: 〈http://legendas.tv/legenders〉. Acesso em: 2 abr. 2018. 
Figura 3- No 'guia de legendagem' disponibilizado pelo grupo InSubs, os fãs dão dicas de tradução. TUTORIAL PARA LEGENDAS
Tradução / Sincronia / Revisão
[InSUBs]

Qualidade é InSUBstituíve

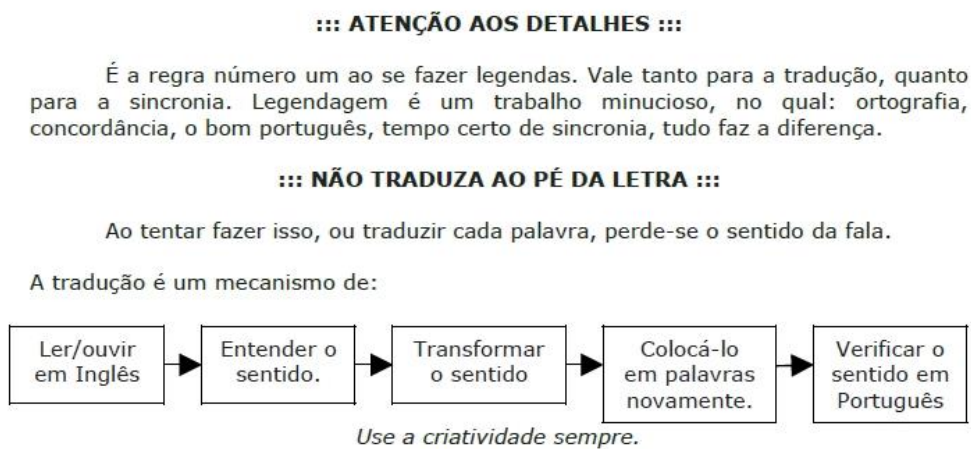

Fonte: Legendas.TV ${ }^{22}$.

Por fim, podemos observar a capacidade dos fãs em produzir conteúdos que ajudam na divulgação e propagação das legendas. Todas as postagens do Legendas.TV seguem um padrão, as legendas são acompanhadas da foto promocional da temporada que está sendo legendada, título da série, formato do arquivo, temporada e episódio, número de downloads e data de publicação. Ao acessar a seção referente à postagem é possível encontrar novas informações como, por exemplo, a sinopse de série e dados mais específicos dos arquivos. Algumas equipes também mantêm blogs ${ }^{23}$ com resenhas das narrativas ficcionais seriadas estadunidenses e análises sobre o processo de tradução e trabalho colaborativo dos fãs. Nesse contexto, os fãs sistematizam as informações pertinentes relacionadas aos conteúdos e contribuem para a organização do site e a navegabilidade dos usuários. Os textos produzidos por algumas equipes também ressaltam a produção crítica e criativa dos telespectadores ávidos em que o processo de tradução das séries serve de ponto de partida para outras práticas da cultura de fãs.

De acordo Ferrés e Piscitelli (2015), a dimensão referente aos processos de interação abrange a habilidade de selecionar, revisar e autoavaliar o próprio consumo/produção midiático; a compreensão do por quê determinados meios, produtos ou conteúdos são apreciados, a capacidade de executar um trabalho colaborativo mediante a conectividade e o conhecimento das possibilidades legais de reclamação diante do descumprimento das normas

\footnotetext{
${ }^{22}$ Disponível em: <http://legendas.tv/legenders>. Acesso em: 1 jul. 2018.

${ }^{23}$ Disponível em: <http://insubs.com/blog>; <queensofthelab.tk>;<maniacs.cf>. Acesso em: 1 jul. 2018.
} 
vigentes em termos audiovisuais. Como discutimos anteriormente, os guias disponibilizados pelos fãs apresentam informações técnicas sobre a produção de legendas. Por exemplo, quais softwares são usados na visualização dos episódios e na inserção das traduções. O tutorial explica, por meio de textos e capturas de tela, todas as configurações e os comandos básicos dos programas. Porém, os guias também reforçam a importância da qualidade das legendas. No capítulo dois do 'Guia de Legendação Tradução e Sincronia', a equipe Nerds ressalta que a tradução não deve ser feita de maneira literal (NERDS, 2015, p.2-12). Os fãs explicam qual é o propósito da legenda e como esta prática se diferencia das outras.

Um aspecto que particularmente diferencia a produção de legendas da tradução de qualquer outra obra é a existência de um tempo limitado para leitura. Há uma tendência, especialmente nos iniciantes, de traduzir da forma mais completa possível, incluindo todos os termos do original. É importante notar, no entanto, que pouco interessa uma tradução primorosa se esta não permanecer na tela tempo suficiente pra ser lida (NERDS, 2015, p.7).

Neste sentido, podemos observar o entendimento crítico que os fãs têm do conteúdo que estão produzindo. Isto é, desde o formato até o modo como ele será consumido pelo público, refletindo quais aspectos devem ser considerados para que o conteúdo cumpra a sua função de forma eficaz.

A dimensão processos de interação também está presente na curadoria feita pelos legenders. Conforme explica Guga, as séries que serão legendadas são selecionadas de acordo com critérios predefinidos tais como o repertório do fã/equipe e a popularidade da trama (inCALAZANS, 2011, ONLINE). A escolha não é feita de forma aleatória, os legenders precisam ter familiaridade com o universo ficcional da atração e um público alvo interessado no conteúdo. Dessa forma, essas questões são previamente pensadas pelos fãs antes de solicitarem a 'reserva' do programa aos administradores do Legendas.TV.

Outro ponto que vai ao encontro das discussões de Ferrés e Piscitelli (2015) é o trabalho colaborativo que envolve a produção das legendas. O perfil da equipe United no Legendas.TV, por exemplo, tem a seguinte frase em destaque: Legendar é dividir o conhecimento, é ajudar, é disseminar cultura. No caso das equipes, cada fã possui uma função específica e uma escala de séries. Por exemplo, um legender sempre ficará responsável por sincronizar as legendas da $13 .^{a}$ temporada de Grey's Anatomy e revisar os arquivos finais da 7. ${ }^{a}$ temporada de Scandal (ABC, 2012-2018). Segundo Guga, a partir de reuniões via Skype e/ou serviços de mensagens instantâneas a função de cada fã é definida de acordo com 
suas aptidões (CALAZANS, 2011, ONLINE). Todas as etapas da produção das legendas são feitas de forma colaborativa e virtualmente. Como explica o legender:

A legendagem é feita toda através (sic) da internet. Às vezes rola uns encontros físicos, como aconteceu entre alguns integrantes da equipe na Campus Party deste ano, mas não especificamente para legendar. Se torna inviável fazer a legendagem fisicamente, uma vez que temos pessoas de todo o Brasil na equipe (in CALAZANS, 2011, ONLINE).

Por fim, os fãs têm conhecimento das leis e dos riscos que envolvem a produção de legendas. Esta questão pode ser observada na forma como os legenders se identificam no Legendas.TV, o conteúdo é creditado por pseudônimos para preservar o anonimato dos fãs.

Figura 4- Os legenders adotam pseudônimos para evitar possíveis processos dos canais e produtoras.

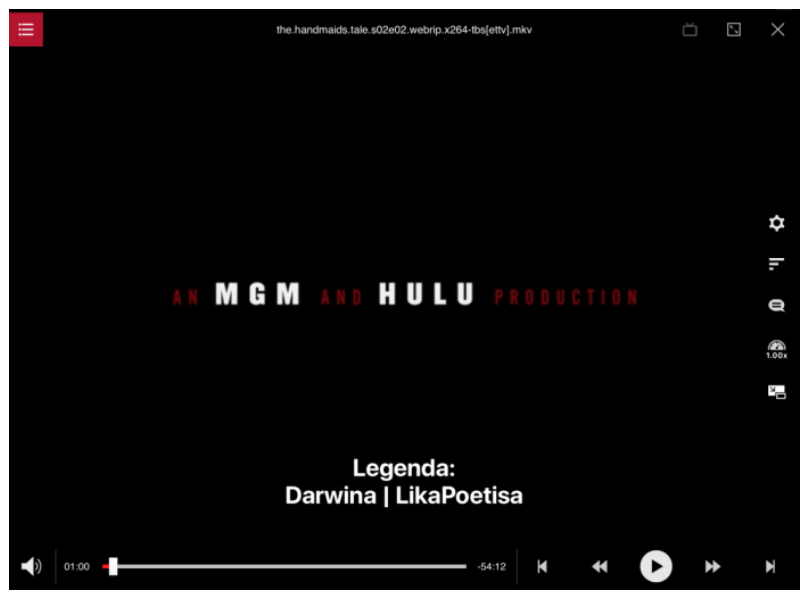

Fonte: Legendas. $\mathrm{TV}^{24}$.

De acordo com Guga, a medida ajuda a "[...] manter o trabalho mais low profile possível para evitar qualquer tipo de estresse que isso possa causar" (in CALAZANS, 2011, ONLINE). O fã também ressalta que no Brasil as leis sobre propriedade intelectual, no âmbito da Internet, são abertas a várias interpretações (in CALAZANS, 2011, ONLINE).

A constituição no Brasil é bem irregular em relação à legenda. Enquanto alguns artigos falam que a legenda é ilegal, outros falam que não é. Já sofremos muito com a APCM que já tentou fechar o Legendas.TV. Antes disso, tinha a ADEPI que todo ano tentava alguma coisa. No entanto, por mais que ameacem, não tem como provarem que o que fazemos é ilegal ou não devido a essa irregularidade na constituição (CALAZANS, 2011, ONLINE).

${ }^{24}$ Disponível em: <https://goo.gl/MdVbEkh>. Acesso em: 2 abr. 2018. 
Nesse contexto os legenderstêm compreensão das leis e dos possíveis riscos que a distribuição das legendas online pode trazer. A partir disso, os fãs tomam medidas preventivas como a adoção de pseudônimos e redes VPN (Virtual Private Network), entre outras ações que dificultam o rastreamento das informações, mesmo que momentaneamente.

\section{CONSIDERAÇÕES FINAIS}

A análise das dimensões da competência midiática que estão em operação no site Legendas.TV reforçam algumas questões importantes nas práticas dos fãs de ficção seriada no ambiente de convergência. Além do conteúdo produzido diariamente pelos legenders, a plataforma apresenta uma arquitetura operacional eficaz que dialoga diretamente com a proposta dos fãs. Nesse sentido, a forma como as informações são dispostas na página, a localização das seções e a navegabilidade intuitiva materializam o domínio técnico que os legenderstêm da tecnologia. Isto é, o site foi estruturado a partir das necessidades e potencialidades do conteúdo produzido pelos fãs.

Outro ponto que chama a atenção na análise das dimensões é o processo colaborativo que envolve as legendas. Os guias disponibilizados pelas equipes têm o objetivo de compartilhar o conhecimento com outros fãs para que todos possam ajudar de alguma forma. As tarefas, tais como tradução, sincronia e revisão, também são divididas em grupo, reforçando a troca mútua de interesses dos legenders. Desta forma, o Legendas.TV materializa a capacidade dos fãs de ficção seriada em se mobilizarem em torno de objetivos comuns. Além de produzirem o conteúdo, os legenders refletem de modo crítico sobre as legendas que estão sendo compartilhadas. Todo processo de produção é avaliado, considerando questões relacionadas aos aspectos técnicos, textuais e linguísticos do processo de tradução. O conteúdo vai além da tradução de um idioma para o português, mas abrange o contexto ficcional e a proposta de cada atração.

Por fim, é importante ressaltar que as dimensões da competência midiática discutidas neste trabalho estão em operação especificamente neste recorte de pesquisa. Não podemos afirmar que elas serão identificadas na análise, por exemplo, das legendas produzidas pelos fãs de filmes no reality shows no Legendas.TV. Entretanto, a interseção de conceitos com o da competência midiática nos ajudam a compreender o caráter multidisciplinar da área. 


\section{REFERÊNCIAS}

BENNETT, L. Tracing Textual Poachers: reflections on the development of fan studies and digital fandom. Journal of Fandom Studies, v. 2, n.1, p.5-20, 2014. Disponível em:

<https://bit.ly/2Gywpfh>. Acesso em: 17 dez. 2018.

BORGES, G.et al. Fãs de Liberdade, Liberdade: curadoria e remixagem na social TV. In: LOPES, M. I. V. (org.). Por uma teoria de fãs da ficção televisiva brasileira II: práticas de fãs no ambiente da cultura participativa. Porto Alegre: Sulina, 2017.p. 93-135.

CALAZANS, R. Um fã conta como é a rotina de uma equipe de 'legenders'. O Globo,2010, on-line. Disponível em: <https://glo.bo/2ItqmFb>. Acesso em: Acesso em: 17 dez. 2018.

EVANS, A; STASI, M. Desperatelyseekingm ethodology: New directions in fan studies research. Participations- Journal of Audience \& Reception Studies, v. 11, n. 2, p. 4-23, 2014. Disponível em: <https://bit.ly/2IdokgX>. Acesso em: 17 dez. 2018.

FERRÉS, J.; PISCITELLI, A. Competência midiática: proposta articulada de dimensões e indicadores. Lumina, v. 9, n, 1, p. 1-16, 2015. Disponível em: 〈https://goo.gl/3EQnc6>. Acesso em: 17 dez. 2018.

GLEICK, J. A informação: uma história, uma teoria, uma enxurrada. São Paulo: Cia das Letras, 2013.

NERDS. Guia de legendação,tradução e sincronia. 2015, on-line. Disponível em: <http://twixar.me/cs13>. Acesso em: 17 dez. 2018.

G1. Hackers reagem e atacam página após fechamento de site de legendas. 2011,on-line. Disponível em: <https://glo.bo/2H9rAWG> Acesso em: 17 dez. 2018.

HERRERO-DIZ, P. et al. Estudio de lãs competências digitales em el espectador fanespañol. Palabra Clave, v.20, n.4, p.17-947, 2017. Disponível em: 〈https://bit.ly/2uMbGPz>. Acesso em: 17 dez. 2018.

JAMISON, A. Fic - Por que a fanfiction está dominando o mundo. São Paulo: Rocco, 2017.

JENKINS, H.et al. Cultura da Conexão - Criando Valor e Significado por Meio da Mídia Propagável. São Paulo: Aleph, 2014.

JENKINS, H. Invasores do Texto - Fãs e cultura participativa. Rio de Janeiro: Marsupial Editora, 2015.

JENKINS, H. Lendo criticamente e lendo criativamente. Matrizes, v.9, n.1, p. 11-24, 2012.

Disponível em: <https://bit.ly/2JYoU30>. Acesso em: 17 dez. 2018.

JENKINS, H. Cultura da convergência. 2. ed. São Paulo: Aleph, 2008.

LEMOS, A. Ciber-Cultura-Remix. Seminário Sentidos e Processos, 2005, on-line. Disponível em: <https://bit.ly/1Mjnd7a>. Acesso em: 17 dez. 2018.

LIVINGSTONE, S. Whatis media literacy?.Intermedia, v.32, n.3, p. 18-20, 2004. Disponível em: <https://bit.ly/2rzwkO2>. Acesso em: 17 dez. 2018. 
LOPES, M. I. V.et al. A autoconstrução do fã: performance e estratégias de fãs de telenovela na internet. In: LOPES, M. I. V. (Org.). Por uma teoria de fãs de ficção televisiva brasileira. Porto Alegre: Editora Sulina, 2015.p. 17-64.

MARTIN, B. Homens Difíceis - Os Bastidores do processo criativo de Breaking Bad, Família Soprano, MadMen e outras séries revolucionárias. São Paulo: Aleph, 2014.

MASSAROLO, J; MESQUISA, D. Narrativa transmídia e a Educação: panorama e perspectivas. Revista Ensino Superior Unicamp, n.9,p.34-42, 2013. Disponível em: <https://bit.ly/2uRaZ51>. Acesso em: 17 dez. 2018.

MONK, C. From 'English' Heritage to Transnational Audiences: Fan Perspectives and Practices and Why They Matter. In: STONE, Rob; COOKE, Paul (Org.). Screening European Heritage: Creating and ConsumingHistory on Film. London: PalgraveEuropeanFilmand Media Studies, 2016.p. 209-234.

PEARSON, R. Fandom in the Digital Era. Popular Communication: The International Journal of Media and Culture, v. 8, n. 1, p. 84-95, 2010. Disponível em: 〈https://bit.ly/2q5Q7nu>. Acesso em: 17 dez. 2018.

POTTER, J. The Stateof Media Literacy. Journal of Broadcasting \& Electronic Media, v. 54, n.4, p. 675-696, 2010. Disponível em: 〈https://bit.ly/2q6yVyW>. Acesso em: 17 dez. 2018.

PRADO, P. Canal Fox Premium usa legenda "pirata" em exibição oficial de série no Brasil. Pipoca Moderna, 2017, on-line. Disponível em: 〈https://bit.ly/2S859pt〉. Acesso em: 17 dez. 2018.

ROSE, F. The Art of Immersion: Howthe Digital Generation Is Remaking Hollywood, Madison Avenue, and the Way WeTell Stories. New York: W W Norton \& Company, 2011.

ROSENBAUM, Judith; BEENTJES, Johannes; KONIG, Ruben. Mapping Media Literacy: Key concepts and future directions. Journal Annals of the International Communication Association, v.32, p. 313-353, 2016. Disponível em: <https://bit.ly/2GS9KtP>. Acesso em: 17 dez. 2018.

SANDVOSS, C. Fans: The mirror of consumption. Cambridge: Polity, 2005

SCOLARI, C.TransmediaLiteracy: Informal Learning Strategiesand Media Skills in the New Ecologyof Communication. Revista Telos- Cuadernos de Comunicación e Innovación, p. 1-9, 2016. Disponível em: 〈https://goo.gl/1KtnZD>. Acesso em: 17 dez. 2018.

SIGILIANO, D; BORGES, G. Competência Midiática: o ativismo dos fãs de The Handmaid's Tale.Comunicação \& Inovação, v. 19, n. 40, p. 106-122, 2018. Disponível em:

$<$ https://bit.ly/2PeuX58>. 17 dez. 2018.

LEGENDAS. TV. Site Legendas.TV é fechado!. 2009, on-line. Disponível em: <https://bit.ly/2EkxEZq>. Acesso em: 17 dez. 2018.

THOMAS, A. Blurring and Breaking through the Boundaries of Narrative, Literacy, and Identity in Adolescent Fan Fiction. In: KNOBEl, M. ; LANKSHEAR, C.(ed.). A new literacies sampler.Nova York: Peter Lang Publishing, 2007, p. 137-166.

THOMPSON,E. The moral economy of the English crowd in theeigh teenth century. Pastand Present, v. 50, n. 1, p. 76-136, 1971. Disponível em: <https://bit.ly/2uxTiYd>. Acesso em: 17 dez. 2018. 
VAL, M. Fox Premium é acusado de usar legenda inSana tirada da internet. Jovem Nerd, 2017, online. Disponível em: <http://bit.ly/2lShcMq>. Acesso em: 17 dez. 2018.

Daiana Sigiliano

Doutoranda e mestre em Comunicação pela Universidade Federal de Juiz de Fora. Membro do grupo do Grupo de Pesquisa em Comunicação, Arte e Literacia Midiática da Universidade

Federal de Juiz de Fora e do Grupo de Pesquisa em Tecnologia, Comunicação e Ciência Cognitiva da Universidade Federal do Amapá. Pesquisadora do Observatório da Qualidade no Audiovisual e Rede brasileira de pesquisadores de ficção televisiva (Obitel).

Gabriela Borges

Mestre e Doutora em Comunicação e Semiótica pela PUC-SP, com estágios nas Universidades Autônoma de Barcelona, Dublin Trinity College e Algarve. Pós-doutora pela Universidade do Algarve, em Portugal. Professora e vice coordenadora do Programa de PósGraduação em Comunicação da Universidade Federal de Juiz de Fora. Coordenadora do Observatório da Qualidade no Audiovisual e integrante da Rede Euroamericana de Alfabetização Midiática, sendo coordenadora da equipe brasileira.

\section{(-) $\mathbb{Q} \Theta(0)$}

Esta obra está licenciado com uma Licença

Creative Commons Atribuição-NãoComercial-CompartilhaIgual 4.0 Internacional 